SCIDiC

\section{Association between Teeth Requiring Endodontic Therapy and Presence of Periapical Lesion - A Retrospective Analysis}

Research Article

Srujana Hemmanur ${ }^{1}$, Iffat $\mathrm{Nasim}^{2 *}$, Sowmya $\mathrm{K}^{3}$

${ }^{1}$ Department of Conservative Dentistry and Endodontics, Saveetha Dental College, Saveetha Institute of Medical and Technical Sciences, Saveetha University, Chennai, India.

${ }^{2}$ Professor and Head, Department of Conservative Dentistry and Endodontics, Saveetha Dental College, Saveetha Institute of Medical and Technical Sciences, Saveetha University, Chennai, India.

${ }^{3}$ Senior Lecturer, Department of Conservative Dentistry and Endodontics, Saveetha Dental College, Saveetha Institute of Medical and Technical Sciences, Saveetha University, Chennai, India.

\title{
Abstract
}

\begin{abstract}
Aim: The aim of the study was to find an association between the teeth requiring endodontic management and changes in the periapical tissues of involved teeth with confounding factors like systemic illness and socio-demographic factors like age and gender. Materials and Methods: The current study is a retrospective analysis. Data from 86,000 patient records were sieved. Pre-op radiographs of mandibular first molars that were endodontically treated were evaluated to assess the presence of radiological changes in the periapical region. The entered data was tabulated and analysed through SPSS. Frequency distribution tables were made and Chi square test with a level of significance of $<0.05$ was performed to establish a correlation between the tooth requiring multi-visit root canal therapy and periapical radiolucency, age, gender, and status of systemic health of the patient.

Results: A total of 829 samples were included. A statistical significance is found in the development of periapical radiolucencies in patients with systemic disease. No correlation between age, gender and tooth is found with the presence of periapical changes. Conclusion: Within the limitations of the study,the association of the presence of periapical lesion with endodontic therapy is not significant in mandibular molars. It can be concluded that systemic health of the patient has an effect on the changes in the periapical regions. Systemic health needs consideration in the formulation of a better protocol to ensure success rates of endodontic therapy.
\end{abstract}

Keywords: Endodontic Therapy; Periapical lesion; Root Canal Treatment; Radiolucency.

\section{Introduction}

Apical periodontitis is an inflammatory disease affecting periradicular tissues and they arise from infection of pulp [1]. The disease of pulp can arise from bacterial, thermal or mechanical insult [2]. It isn't surprising to see that apical periodontitis is the most common sequela of dental caries with nearly $50 \%$ of cases with dental caries progressing to apical periodontitis stage [3]. It is amongst the common causes of loss of tooth. Identification and location of dental caries and its progression to involve the sensitive pulpal tissue by using remineralising agents act as a preventive measure $[4,5]$. Other than dental caries, trauma can cause apical periodontitis in association with or without calcified canals $[6,7]$.
The management of traumatic injuries depend on pulp sensibility and nature and extent of the traumatic injury $[8,9]$.

The principal objective of carrying out endodontic therapy is to prevent the extraction of the affected tooth, to prolong its life and help in the maintenance of the arch integrity. Endodontic therapy commonly known as the root canal treatment basically involves the removal of diseased pulp, removal of microorganisms, maximal disinfection of the canal space using chemicals of either natural or artificial origin in the form of intracanal irrigants and/or medicaments to prevent reinfection, minimal biomechanical preparation of the root canals and filling of these canal spaces with a biocompatible material [10-17]. The importance of post endodontic restoration cannot be overlooked. Final restorations

*Corresponding Author:

Iffat Nasim,

Professor and Head, Department of Conservative Dentistry and Endodontics, Saveetha Dental College, Saveetha Institute of Medical and Technical Sciences, Saveetha University,

Chennai, India.

Tel: +919940063567

E-mail: iffatnasim@saveetha.com

Received: November 05, 2020

Accepted: November 18, 2020

Published: November 20,2020

Citation: Srujana Hemmanur, Iffat Nasim, Sowmya K. Association between Teeth Requiring Endodontic Therapy and Presence of Periapical Lesion - A Retrospective Analysis. Int J Dentistry Oral Sci. 2020;S10:02:003:13-18. doi: http://dx.doi.org/10.19070/2377-8075-SI02-010003

Copyright: Iffat Nasim ${ }^{\circ} 2020$. This is an open-access article distributed under the terms of the Creative Commons Attribution License, which permits unrestricted use, distribution and reproduction in any medium, provided the original author and source are credited. 
with restorative resins, veneers or laminates, various types of crowns to provide function and prevent reinfection by constant seeping ought to be done that ensure the success of endodontic treatment $[18,19]$.

The bacterial bypass from the canal space to the periradicular tissues causes apical periodontitis. The host defence and virulence of microorganisms organised in the form of biofilm are among the important factors that cause the spread of the disease as endodontic disease is a biofilm-mediated infection [20]. The presence or increase in the periapical radiolucency even after the endodontic therapy is performed indicates compromised removal of microorganisms from the canal systems [21].

A systematic review concluded the prevalence of a high percentage of periapical radiolucencies with a broad equivalence of one radiolucency per patient reporting with dental pain [22]. Periapical changes have been reported in the range of $3-10 \%$ in teeth requiring endodontic therapy $[22,23]$.

The aim of the present study was to find an association between the teeth requiring endodontic management and changes with respect to the periapical tissues of the involved teeth with confounding factors like systemic health and socio demographic factors like age and gender.

\section{Materials and Methods}

The current study was performed at a Dental hospital setting. An institutional committee approval with the approval number SDC/ SIHEC/2020/DIASDATA/0619-0320 was obtained as the study required the access to personal data of the patients.

It was a retrospective analysis. The data from a period of June 2019 to March 2020 was accessed. A total of 86,000 case sheets were acquired. All the case sheets were reviewed by 2 reviewers and cases with endodontic management of mandibular first molars were sieved through. Cases where a single visit RCT was performed were excluded from the study as these are strictly prohibited in the management of teeth with periapical radiolucencies.

The samples included both male and female patients within the age groups of 18 to 60 years. The presence or absence of periapical radiolucency was assessed in the pre-op radiographs of the mandibular first molars included by the 2 reviewers and in case of a controversy was resolved by a final evaluator. The age, gender and status of general systemic health of the patients fitting the inclusion criteria were also noted down. Cross-verification and removal of duplicate records were done to minimise the sampling bias.

All the data was entered in Microsoft Excel and exported to IBM SPSS Software 20. Incomplete data was verified from the concerned patient's case sheet or the department and filled accordingly, otherwise excluded from the study.

The tabulated and converted data is analysed through SPSS. Frequency distribution tables were made and a Chi-Square test was performed in order to find a correlation between the tooth requiring multi-visit root canal therapy and status of periapical radiolucency, age,gender and status of systemic health of the patient.

Statistical package for social sciences version 20, software from the University of Stanford (Norman H Nie, C. Hadlai, Hull and Dale $\mathrm{H}$ ) was used for all statistical analyses of the present study. Frequency distribution was assessed and a Chi square test with a level of significance of $<0.05$ was performed to establish a correlation between the tooth requiring multi-visit root canal therapy and periapical radiolucency, age, gender, and status of systemic health of the patient.

\section{Results and Discussion}

The parameters that were included in the evaluation were age, gender, presence/absence of lesion and systemic illness (if any) along with the tooth of interest. The samples included a total of 829 patients' records.

A total of 412 records (49.7\%), 206 (24.8\%), 138 (16.6\%) and 73 $(8.8 \%)$ of records belonged to patients of the age groups of 18 30 years, 31-40 years, $41-50$ years and $>51$ years respectively [Figure 1]. 445 records $(53.7 \%)$ belonged to male while 384 records $(46.3 \%)$ of females were found [Figure 2]. A total of 410 teeth that were evaluated were mandibular left first molars $(49.5 \%)$ while 445 records $(50.5 \%)$ were mandibular right first molars [Figure 3]. Periapical lesion was not appreciated in 631 teeth $(76.1 \%)$ while $23.9 \%$ of the teeth presented with periradicular changes [Figure 4]. No systemic illness was reported by 787 patients (

Figure 1. Bar chart denotes the frequency distribution of the age of the patients who were treated with endodontic therapy in the mandibular first molars. The X-axis denotes the age of the patient and Y-axis denotes the number of teeth indicated for RCT.It can be inferred that 412 records (49.7\%) (yellow), $206(24.8 \%)$ (blue), 138 (16.6\%) (purple) and 73 (8.8\%) (navy blue) of records belonged to patients of the age groups of 18-30 years, 31-40 years, 41-50 years and >51 years respectively.

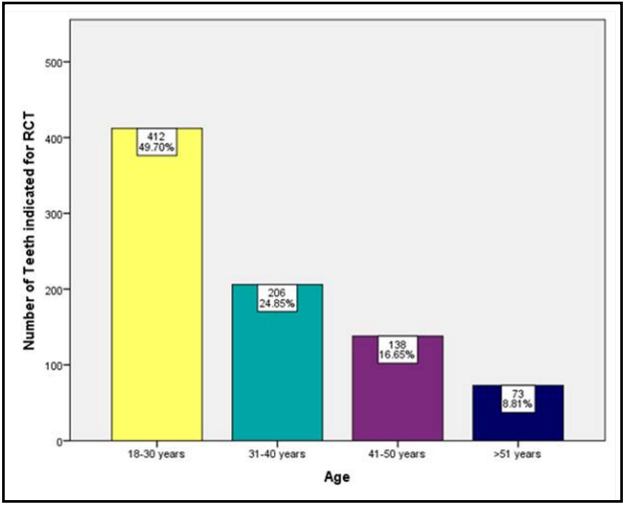


Figure 2. Bar chart denotes the frequency distribution of the gender of the patients who were treated with endodontic therapy in the first mandibular molars. The $\mathrm{X}$-axis denotes the gender of the patient and $\mathrm{Y}$-axis denotes the number of teeth indicated for RCT. 445 records (53.7\%) belonged to males (blue) while 384 records (46.3\%) were that of females (orange).

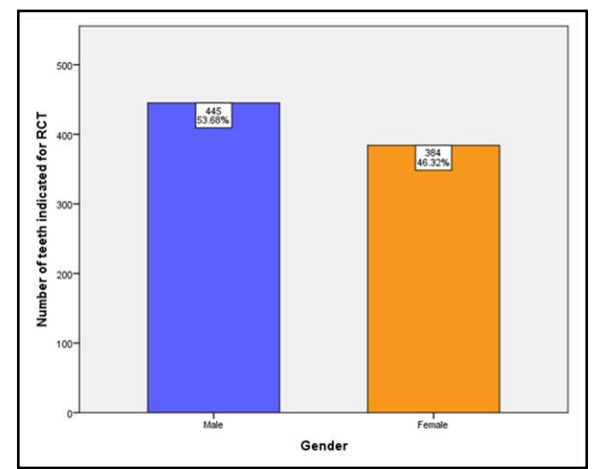

Figure 3. Bar chart denotes the frequency distribution of the type of the tooth of the patient which was treated with an endodontic therapy in the first mandibular molars. The X-axis denotes mandibular first molar (Left/right) and Y-axis denotes the number of teeth indicated for RCT. 410 teeth that were evaluated were mandibular left first molars (49.5\%) (grey) while 445 records $(50.5 \%)$ were mandibular right first molars (sky blue)

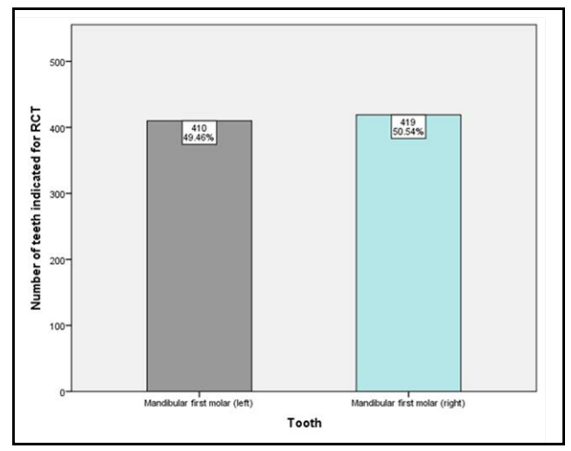

Figure 4. Bar chart denotes the frequency distribution of the presence/absence of periapical radiolucency as appreciated by the reviewers by analysing pre-operative radiographs. The $\mathrm{X}$-axis denotes the radiographic change in the periapical region and Y-axis denotes the number of teeth indicated for RCT. Periapical lesion was not appreciated in 631 teeth (76.1\%) (green ) while $23.9 \%$ of the teeth presented with periradicular changes (maroon).

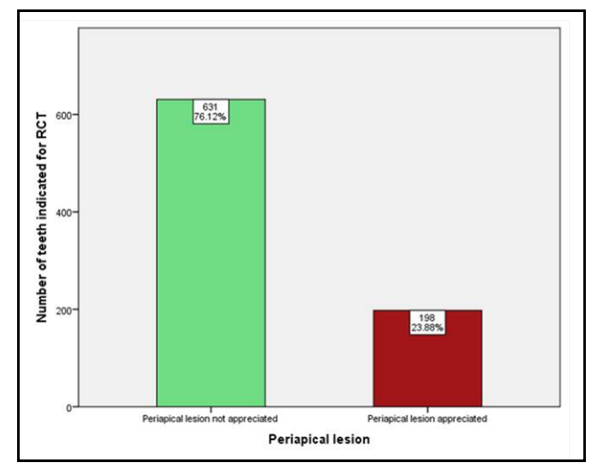

$94.9 \%$ ) while $5.1 \%$ of the patients that came upto 42 patients reported the presence and nature of the systemic illness [Figure 5].

Table 1 represents the data compilation. No significant association in the age or tooth with appreciation of periapical radiolucency could be deduced. ( $p$ value $>0.05$ ). Also, no association is found in the gender of the patient and the presence of periapical lesion as a chi-square value of $\mathrm{p}>0.05$ is obtained [Table 1]. A positive association of significance value is found between the presence of systemic illness in the development of periapical radiolucencies with a $\mathrm{p}$ value $<0.05$ on chi-square test. [Figure 6]

In the present study, no significance between the gender and the presence of systemic illness in development of periapical radio- lucencies was found ( $\mathrm{p}$ value $>0.05$; Chi square test). No significant association in age or tooth with appreciation of periapical radiolucency was found. However, the chance of the presence of periapical lesions in patients with systemic illnesses has been observed to be greater.

Apical periodontitis is a sequel of pulpal infection that presents itself as a manifestation when the host defense response is challenged by the microorganisms ensuing from the root canal system [3]. It basically is a dynamic encounter between body response and virulence of microbiota that results in the occurrence of disease when a loss of equilibrium occurs at the periapex [24]. Microorganisms are the etiological agents for apical periodontitis and their variable constitution as biofilms and composition with 
Figure 5. Bar chart denotes the frequency distribution of the nature of the systemic health of the patients who underwent endodontic therapy of mandibular first molars as reported by the patient. The $\mathrm{X}$-axis denotes the systemic health status and Y-axis denotes the number of teeth indicated for RCT. No systemic illness was reported by 787 patients ( $94.9 \%$ ) (pink) while $5.1 \%$ of the patients that came upto 42 patients reported the presence and nature of the systemic illness (blue).

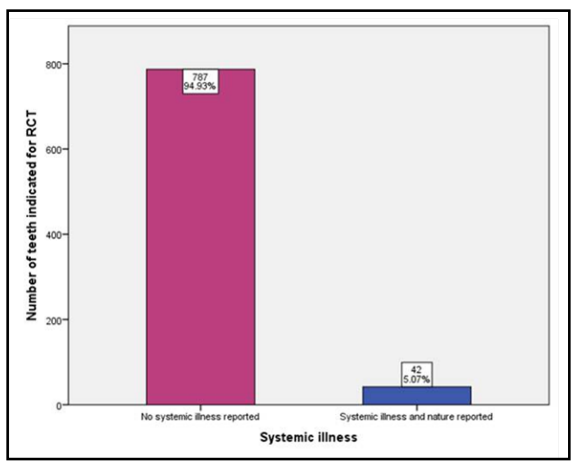

Table 1. Association of the presence of periapical lesion with variables like age, gender, tooth type and nature of systemic illness. Upon analysis, it can be seen that except that nature of systemic health, all the other factors have not got a significant association between the presence/absence of periapical lesions and the factor studied.

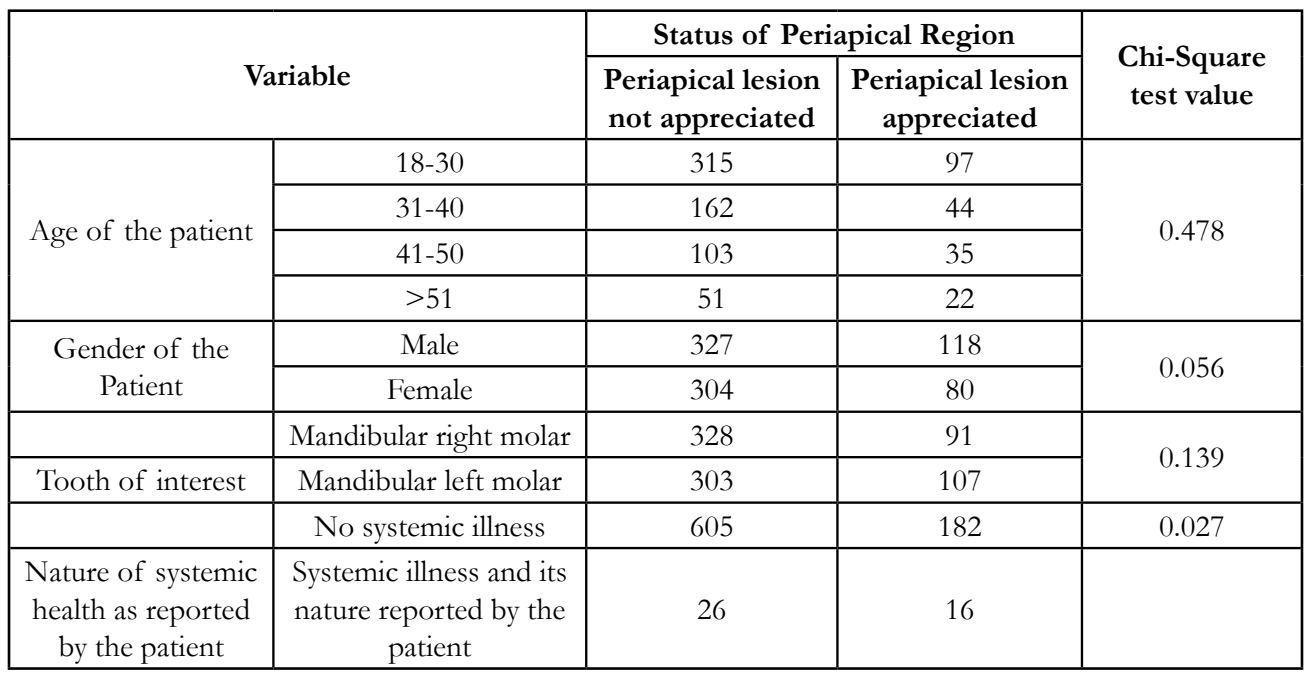

Figure 6. Bar chart showing the correlation between the nature of systemic health and presence/absence of periapical lesion. $\mathrm{X}$-axis denotes the nature of systemic health of the patients in whom endodontic therapy was performed and $\mathrm{Y}$-axis denotes the number of teeth indicated for RCT. Teeth with no periapical changes (green) and teeth with periapical changes (maroon).The patients who reported systemic illness are more prone to development of periapical lesions. A majority of the patients who did not report systemic illness did not develop periapical lesions as well. This is a significant finding as $\mathrm{p}$ value $=0.027$, Chi-Square test $\mathrm{p}<0.05)$.

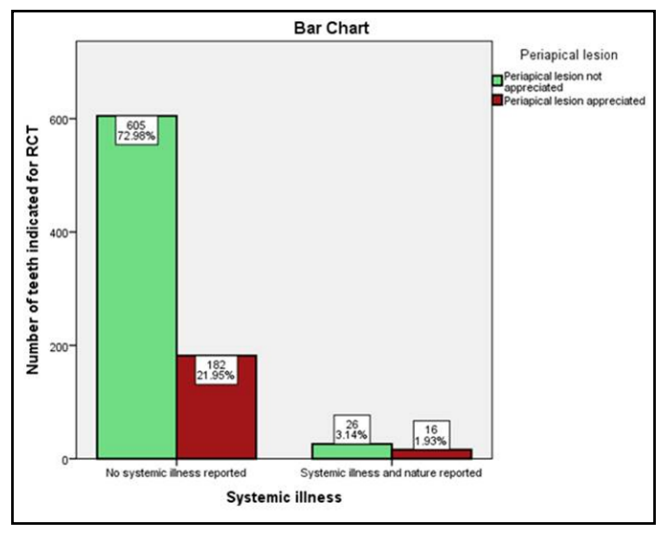

anaerobes in predominance have been reported [25-28]. The general stages of disease progression can be described as the healthy tissue presents with inflammation that progresses to necrosis, infection and finally tissue destruction occur [29]. Hence, periapical inflammation is a direct result from the interaction of bacteria in the untreated infected root canal system and the host's immune status.

In a study conducted previously, no association was found in age and presence of periapical radiolucency or its size [30]. In the present study, out of 829 cases, 129 cases presented with periapical changes. Out of the age groups, a maximum of $28.8 \%$ of cases 
(97 cases) were found in the age group of 18-30 years [Table 1].

In a study conducted by Sousa et al., a higher percentage of teeth with apical periodontitis belonged to the gender of males [31]. Similar results have been found in the present study, however they weren't of statistical significance. Out of 198 cases that presented with a periapical lesion; $59.5 \%$ of cases were males while $40.4 \%$ were female patients. However, another study presented with a contradictory result [32] where females were found to have more periapical radiolucencies.

The systemic health and its connection with oral chronic inflammatory diseases like periodontal disease or endodontic infection of periapical regions (aka apical periodontitis) have been studied thoroughly through the years. There seems to be an established connection between the periodontal disease and apical periodontitis as both are chronic infections of the oral cavity with gram negative bacteria is abundance and local rise of inflammatory mediators which are also associated with systemic diseases [33]. For instance, matrix metalloproteinase-3 (MMP-3) is proven to play an essential role in pulpal tissue inflammation, destruction, development of periapical lesions, remodeling and resorption of bone and healing responses [34].

Number of studies have been performed to evaluate the effect of diabetes mellitus and apical periodontitis, the first human study as done by Bender in 1963 [35]. A critical review by Tiburcio et al found the data inconclusive as among the human trials both significant and insignificant association was reported by the authors [36]. Human studies where a significant association between the presence, size, healing of apical periodontitis and periapical radiolucency and success of the endodontic therapy with diabetes mellitus were found [37-44]. However, no significant association has been reported as well [45-47]. Another systematic literature review concluded in the similar fashion indicating the association of diabetes mellitus and apical periodontitis to be controversial or rather a mere coincidence [48].

The association of hypertension and prevalence of apical periodontitis has been negated $[49,50]$. Contrary to this, an increased appearance of radiolucent regions is hypertensive patients has been reported too $[51,52]$. In the present study, a significance was found as out of 42 patients who reported with systemic illness nearly $40 \%$ of the patients presented with changes in periapical region, a $\mathrm{p}$ value of $<0.05$ (Chi-square test).

The limitations of the current study was limited sampling, small sample size, 2-D radiographic technique and failure to measure the size of the periapical changes. Though the connection between systemic health conditions cannot be proven with utmost certainty, it cannot be completely denied as well. Hence, more clinical studies on a larger scale need to be performed worldwide such that the association of periapical changes with systemic illness and other demographic details be confirmed or denied confirmedly.

\section{Conclusion}

Within the limitations of the study, the association of the presence of periapical lesion with endodontic therapy is not significant in mandibular molars. It can be concluded that systemic health of the patient has an effect on the changes in the periapical tissues. The healing response and prognosis of the endodontic therapy depends on not only the treatment protocol adopted and materials used, but also upon the general health status of the patient.

\section{Clinical Significance}

The status of systemic health of a patient along with demographic factors like age and gender have certainly influenced the healing process in humans. The association of these factors with the periapical inflammation and infection can thus help in formulation of a better clinical protocol that shall ensure the success of endodontic therapies in the long run. It will also help as an indicator that shall help in evaluating the success and survival rates of endodontic therapies in a general population.

\section{Acknowledgement}

We would like to acknowledge Mr. Arun's contribution (IT Department) for helping us to access the required data.

\section{References}

[1]. Hargreaves KM, Berman LH. Cohen's pathways of the pulp expert consult. Elsevier Health Sciences; 2015 Oct 2;928.

[2]. Sureshchandra B, Gopikrishna V. Grossman's Endodontic Practice. 13th edtn. (2014) Wolters Kluwer Health.

[3]. Nair PN. Pathogenesis of apical periodontitis and the causes of endodontic failures. Crit Rev Oral Biol Med. 2004 Nov 1;15(6):348-81.Pubmed PMID: 15574679.

[4]. Rajendran R, Kunjusankaran RN, Sandhya R, Anilkumar A, Santhosh R, Patil SR. Comparative Evaluation of Remineralizing Potential of a Paste Containing Bioactive Glass and a Topical Cream Containing Casein Phosphopeptide-Amorphous Calcium Phosphate: An in Vitro Study. Pesqui. Bras. Odontopediatria Clin. 2019;19.

[5]. Nandakumar M, Nasim I. Comparative evaluation of grape seed and cranberry extracts in preventing enamel erosion: An optical emission spectrometric analysis. J Conserv Dent. 2018 Sep-Oct;21(5):516-520.Pubmed PMID: 30294113.

[6]. Kumar D, Antony S. Calcified Canal and Negotiation-A Review. Res J Pharm Technol. 2018;11(8):3727-30.

[7]. Jose J, Subbaiyan H. Different Treatment Modalities followed by Dental Practitioners for Ellis Class 2 Fracture-A Questionnaire-based Survey. Open Dent. J. 2020 Feb 18;14(1).

[8]. Janani K, Palanivelu A, Sandhya R. Diagnostic accuracy of dental pulse oximeter with customized sensor holder, thermal test and electric pulp test for the evaluation of pulp vitality: an in vivo study. Braz. Dent. Sci. 2020 Jan 31;23(1):8-11.

[9]. Rajakeerthi R, Ms N. Natural Product as the Storage medium for an avulsed tooth-A Systematic Review. Cumhur. Dent.J. 2019;22(2):249-56.

[10]. Grossman LI. Endodontic practice, ed 10. Endod.1982;8: S34-5.

[11]. Muliyar S, Shameem KA, Thankachan RP, Francis PG, Jayapalan CS, Hafiz KA. Microleakage in endodontics. J Int Oral Health. 2014 Nov;6(6):99104.

[12]. Noor S, Others. Chlorhexidine: Its properties and effects. Res J Pharm Technol.2016; 9(10):1755-60.

[13]. Manohar MP, Sharma S. A survey of the knowledge, attitude, and awareness about the principal choice of intracanal medicaments among the general dental practitioners and nonendodontic specialists. Indian J Dent Res. 2018 Nov-Dec;29(6):716-720.Pubmed PMID: 30588997.

[14]. 14. Teja KV, Ramesh S. Shape optimal and clean more. Saudi Endod J. 2019 Sep 1;9(3):235.

[15]. 15. Ramamoorthi S, Nivedhitha MS, Divyanand MJ. Comparative evaluation of postoperative pain after using endodontic needle and EndoActivator during root canal irrigation: A randomised controlled trial. Aust Endod J. 2015 Aug;41(2):78-87.Pubmed PMID: 25195661.

[16]. Ramanathan S, Solete P. Cone-beam Computed Tomography Evaluation of Root Canal Preparation using Various Rotary Instruments: An in vitro Study. J Contemp Dent Pract. 2015 Nov 1;16(11):869-72.

[17]. Siddique R, Sureshbabu NM, Somasundaram J, Jacob B, Selvam D. Quali- 
tative and quantitative analysis of precipitate formation following interaction of chlorhexidine with sodium hypochlorite, neem, and tulsi. J Conserv Dent. 2019 Jan-Feb;22(1):40-47.Pubmed PMID: 30820081.

[18]. Ravinthar K. Recent advancements in laminates and veneers in dentistry. Res J Pharm Technol. 2018;11(2):785-7.

[19]. Hussainy SN, Nasim I, Thomas T, Ranjan M. Clinical performance of resinmodified glass ionomer cement, flowable composite, and polyacid-modified resin composite in noncarious cervical lesions: One-year follow-up. J Conserv Dent. 2018 Sep-Oct;21(5):510-515.Pubmed PMID: 30294112.

[20]. Jhajharia K, Parolia A, Shetty KV, Mehta LK. Biofilm in endodontics: A review. J Int Soc Prev Community Dent.2015 Jan;5(1):1-12.

[21]. Siqueira Jr JF, Rôças IN. Clinical implications and microbiology of bacterial persistence after treatment procedures. J Endod. 2008 Nov 1;34(11):1291301.

[22]. Pak JG, Fayazi S, White SN. Prevalence of periapical radiolucency and root canal treatment: a systematic review of cross-sectional studies. J Endod. 2012 Sep 1;38(9):1170-6.

[23]. Maslamani M, Behbahani J, Mitra AK. Radiographic evaluation and predictors of periapical lesions in patients with root-filled and nonroot-filled teeth in Kuwait. Indian J Dent Sci. 2017 Oct 1;9(4):237.

[24]. Stashenko P, Teles R, d'Souza R. Periapical inflammatory responses and their modulation. Critical Reviews in Oral Biology \& Medicine. 1998 Oct;9(4):498-521.

[25]. KAKEHASHI S, STANLEY HR, FITZGERALD RJ. THE EFFECTS OF SURGICAL EXPOSURES OF DENTAL PULPS IN GERM-FREE AND CONVENTIONAL LABORATORY RATS. Oral Surg Oral Med Oral Pathol. 1965 Sep;20:340-9.Pubmed PMID: 14342926.

[26]. Ramachandran Nair PN. Light and electron microscopic studies of root canal flora and periapical lesions. J Endod. 1987 Jan;13(1):29-39.Pubmed PMID: 3469299.

[27]. Sundqvist G. Associations between microbial species in dental root canal infections. ORAL MICROBIOL IMMUN. 1992 Oct;7(5):257-62.

[28]. Sundqvist G. Ecology of the root canal flora. J Endod. 1992 Sep 1;18(9):42730.

[29]. Abbott PV. Classification, diagnosis and clinical manifestations of apical periodontitis. Endod Topics. 2004 Jul;8(1):36-54.

[30]. Enriquez FJ, Vieyra JP, Ocampo FP. Relationship between clinical and histopathologic findings of 40 periapical lesions. Dentistry. 2015 Jan 1;5(2):1.

[31]. Correia-Sousa J, Madureira AR, Carvalho MF, Teles AM, Pina-Vaz I. Apical periodontitis and related risk factors: Cross-sectional study. Revista Portuguesa de Estomatologia, Medicina Dentária e Cirurgia Maxilofacial. 2015 Oct 1;56(4):226-32.

[32]. Berlinck T, Tinoco JM, Carvalho FL, Sassone LM, Tinoco EM. Epidemiological evaluation of apical periodontitis prevalence in an urban Brazilian population. Braz Oral Res. 2015;29:51.Pubmed PMID: 25760068.

[33]. Segura-Egea JJ, Castellanos-Cosano L, Machuca G, López-López J, MartínGonzález J, Velasco-Ortega E, et al. Diabetes mellitus, periapical inflammation and endodontic treatment outcome. Med Oral Patol Oral Cir Bucal. 2012 Mar 1;17(2):e356-61.Pubmed PMID: 22143698.

[34]. Teja KV, Ramesh S, Priya V. Regulation of matrix metalloproteinase-3 gene expression in inflammation: A molecular study. J Conserv Dent. 2018 Nov;21(6):592-6.

[35]. BENDER IB, SELTZER S, FREEDLAND J. THE RELATIONSHIP OF SYSTEMIC DISEASES TO ENDODONTIC FAILURES AND TREATMENT PROCEDURES. Oral Surg Oral Med Oral Pathol. 1963 Sep;16:1102-15.Pubmed PMID: 14061146

[36]. Tibúrcio-Machado CD, Bello MC, Maier J, Wolle CF, Bier CA. Influence of Diabetes in the Development of Apical Periodontitis: A Critical Literature Review of Human Studies. J Endod. 2017 Mar;43(3):370-376.Pubmed PMID: 28231976.

[37]. Bender IB, Bender AB. Diabetes mellitus and the dental pulp. J Endod. 2003 Jun 1;29(6):383-9.

[38]. Cheraskin E, Ringsdorf Jr WM. The biology of the endodontic patient 3. Variability in periapical healing and blood glucose. J Oral Med. 1968 Jul;23(3):87-90.

[39]. Fouad AF, Burleson J. The effect of diabetes mellitus on endodontic treatment outcome: data from an electronic patient record. J Am Dent Assoc. 2003 Jan;134(1):43-51.Pubmed PMID: 12555956.

[40]. Britto LR, Katz J, Guelmann M, Heft M. Periradicular radiographic assessment in diabetic and control individuals. Oral Surg Oral Med Oral Pathol Oral Radiol Endod. 2003 Oct;96(4):449-52.Pubmed PMID: 14561970.

[41]. Segura-Egea JJ, Jiménez-Pinzón A, Ríos-Santos JV, Velasco-Ortega E, Cisneros-Cabello R, Poyato-Ferrera M. High prevalence of apical periodontitis amongst type 2 diabetic patients. Int Endod J. 2005 Aug;38(8):564-9.Pubmed PMID: 16011776.

[42]. López-López J, Jané-Salas E, Estrugo-Devesa A, Velasco-Ortega E, MartínGonzález J, Segura-Egea JJ. Periapical and endodontic status of type 2 diabetic patients in Catalonia, Spain: a cross-sectional study. J Endod. 2011 May;37(5):598-601.Pubmed PMID: 21496655.

[43]. Sánchez-Domínguez B, López-López J, Jané-Salas E, Castellanos-Cosano L, Velasco-Ortega E, Segura-Egea JJ. Glycated hemoglobin levels and prevalence of apical periodontitis in type 2 diabetic patients. J Endod. 2015 May 1;41(5):601-6.

[44]. Ueta E, Osaki T, Yoneda K, Yamamoto T. Prevalence of diabetes mellitus in odontogenic infections and oral candidiasis: an analysis of neutrophil suppression. J Oral Pathol Med. 1993 Apr;22(4):168-74.Pubmed PMID: 8391079.

[45]. FALK H, HUGOSON A, THORSTENSSON H. Number of teeth, prevalence of caries and periapical lesions in insulin-dependent diabetics. Eur J dent. 1989 Jun;97(3):198-206.

[46]. Ilgüy M, Ilgüy D, Bayirli G. Dental lesions in adult diabetic patients. N Y State Dent J. 2007;73(1):58-60.

[47]. Marotta PS, Fontes TV, Armada L, Lima KC, Rôças IN, Siqueira JF Jr. Type 2 diabetes mellitus and the prevalence of apical periodontitis and endodontic treatment in an adult Brazilian population. J Endod. 2012 Mar;38(3):297300.Pubmed PMID: 22341063.

[48]. Pérez-Losada FL, Jané-Salas E, Sabater-Recolons MM, Estrugo-Devesa A Segura-Egea JJ, López-López J. Correlation between periodontal disease management and metabolic control of type 2 diabetes mellitus. A systematic literature review. Med Oral Patol Oral Cir Bucal. 2016 Jul 1;21(4):e440-6. Pubmed PMID: 26827070.

[49]. Segura-Egea JJ, Jimenez-Moreno E, Calvo-Monroy C, Ríos-Santos JV, Velasco-Ortega E, Sánchez-Domínguez B, et al. Hypertension and dental periapical condition. J Endod. 2010 Nov 1;36(11):1800-4.

[50]. Martins CM, Sasaki H, Hirai K, Andrada AC, Gomes-Filho JE. Relationship between hypertension and periapical lesion: an in vitro and in vivo study. Braz Oral Res. 2016 Oct 10;30(1):e78.Pubmed PMID: 27737351.

[51]. Wang CH, Chueh LH, Chen SC, Feng YC, Hsiao CK, Chiang CP. Impact of diabetes mellitus, hypertension, and coronary artery disease on tooth extraction after nonsurgical endodontic treatment. J Endod. 2011 Jan;37(1):15.Pubmed PMID: 21146066.

[52]. Mindiola MJ, Mickel AK, Sami C, Jones JJ, Lalumandier JA, Nelson SS. Endodontic treatment in an American Indian population: a 10-year retrospective study. J Endod. 2006 Sep;32(9):828-32.Pubmed PMID: 16934624. 